\title{
MORPHOMETRIC STUDY OF BONY PALATE AMONG DRY SKULLS OF SOUTH INDIA POPULATION
}

\section{Sachin K S ${ }^{* 1}$, Divya $\mathrm{P}^{2}$, Chaitra $\mathrm{D}^{3}$, Martin LA ${ }^{4}$.}

${ }^{* 1}$ Associate Professor, Department of Anatomy, K.V.G Medical College, Sullia, Dakshina Kannada, India.

${ }^{2}$ Lecturer, Department of Anatomy, K S Hegde Medical Academy, Mangaluru, India.

${ }^{3}$ Lecturer, Department of Anatomy, K S Hegde Medical Academy, Mangaluru, India.

${ }^{4}$ Professor, Department of Anatomy, K S Hegde Medical Academy, Mangaluru, India.

\section{ABSTRACT}

Background: Hard palate forms an important area in the skull, between the oral cavity and the nasal cavity. It is formed anteriorly by the palatine process of maxillae and posteriorly by the horizontal plates of palatine bones of both sides, forming a cruciform suture in the midline. The hard palate play a crucial role in articulation of speech and any significant variations in its morphology may lead to alterations in the speech of an individual.

Materials and Methods: The present study was conducted on 50 dry skulls of unknown sex and age obtained from the department of Anatomy, K S Hegde Medical Academy, Mangaluru. Various morphometric measurments were taken from the skull using digital vernier calipers.

Results: The length, breadth and height of the hard palate was $50.45 \mathrm{~mm} \pm 2.86 \mathrm{~mm}, 39.38 \mathrm{~mm} \pm 2.28 \mathrm{~mm}$ and $10.31 \mathrm{~mm} \pm 2.21 \mathrm{~mm}$ respectively. The distance between the greater palatine foramen and middle maxillary suture was $14.80 \mathrm{~mm} \pm 1.14 \mathrm{~mm}$ on right and $14.83 \mathrm{~mm} \pm 1.08 \mathrm{~mm}$ on left side. The position of greater palatine foramen in $82 \%$ of the skulls was opposite $3^{\text {rd }}$ molars and $18 \%$ was between $2^{\text {nd }}$ and $3^{\text {rd }}$ molars. The palatine index showed that, $66 \%$ were Leptostaphyline, $18 \%$ were Mesostaphyline and $16 \%$ were Brachystaphyline The palatine height index showed that $56 \%$ were Chamestaphyline, and $44 \%$ were Orthostaphyline.

Conclusion: The present study identifies the commonest location of greater palatine foramen to be opposite the $3^{\text {rd }}$ maxillary molars which is useful for clinicians to perform procedures on palate. The morphometry is useful in comparing the skulls of various origin.

KEY WORDS: Hard palate, Maxilla, Molar tooth, Morphometry, Skull.

Address for Correspondence: Dr.Sachin K S, Associate Professor, Department of Anatomy, K.V.G Medical College, Sullia, Dakshina Kannada, Karnataka - 574327. Tel No: +91-9611206205.

E-Mail: drsachinks63@gmail.com

Access this Article online

Quick Response code

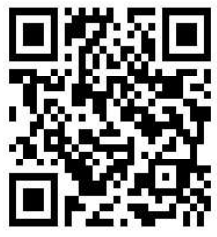

DOI: $10.16965 /$ ijar.2019.240
Journal Information

International Journal of Anatomy and Research

$\left.\begin{array}{ccc}\text { ICV for } 2016 \\ \mathbf{9 0 . 3 0}\end{array}\right) \begin{gathered}\text { ISSN (E) 2321-4287 | ISSN (P) 2321-8967 } \\ \text { https://www.ijmhr.org/ijar.htm } \\ \text { DOI-Prefix: https://dx.doi.org/10.16965/ijar }\end{gathered}$

Article Information

Received: 01 Jun $2019 \quad$ Accepted: 08 Jul 2019

Peer Review: 01 Jun $2019 \quad$ Published (O): 05 Aug 2019

Revised: None Published (P): 05 Aug 2019

\section{INTRODUCTION}

Hard palate forms an important area in the skull, between the oral cavity and the nasal cavity. It is formed anteriorly by the palatine process of maxillae and posteriorly by the horizontal plates of palatine bones of both sides, forming a cruciform suture in the midline [1]. The hard palate play a crucial role in articulation of speech and any significant variations in its morphology may lead to alterations in the speech of an individual. In the embryonic life, the palate develops as primitive palate and permanent 
palate, the junction of which is represented by the incisive fossa. Hence, the contributions from both these parts are of paramount importance for the proper functioning of an individual.

Morphological studies of the cranial bones play an important role in the analysis of skeletal variations, in determining the population history and classification, in studying the relationships between population and in investigations of adaptive and behavioural significance of bone morphology [2].

Greater palatine foramen (GPF) forms an important anatomical landmark along the posterolateral aspect of hard palate. It transmits the greater palatine nerve, a branch of maxillary division of fifth cranial nerve. It carries sensations from the posterior part of hard palate. Greater palatine foramen is of critical importance to dentists, ENT surgeons and maxillofacial surgeons who perform a number of procedures in this region like dental implant placements, local anaesthetic administration, Le Forte osteotomies, sino-nasal surgeries etc [3]. Hence, evaluation of the relative position of GPF is important for injection of local anaesthetic for optimal pain control in maxillofacial and dental surgeries [4].

The aim of the present study was to measure the dimensions of the hard palate ie., length, breadth and height, contribution of the premaxilla and the palatine process in formation of hard palate and position of greater palatine foramen. The observations derived from the present study will help the anthropologists to understand the racial and ethnic differences and the surgeons to localise the position of GPF for various procedures.

\section{MATERIALS AND METHODS}

The present study was conducted on 50 dry skulls of unknown sex and age obtained from the department of Anatomy, K S Hegde Medical Academy, NITTE (Deemed To Be University), Mangaluru. All the skulls were normal and edentulous. The following measurments were taken from the skull using vernier calipers.

- Length of Pre-maxilla (a).

- Length of palatine process of maxilla (b).

- Length of hard palate (c).
- Breadth of hard palate (d).

- Height of hard palate (h).

- Distance between GPF and middle maxillary suture (MMS) (e).

- Position of GPF.

Length of the hard palate was the distance between orale anteriorly (orale is the point at the anterior end of the incisive suture located between the sockets of the two medial maxillary incisors) and the posterior nasal spine posteriorly. Breadth of the hard palate was the distance between the inner borders of the sockets of upper second molars, endomolaria. Height of the hard palate was the maximum arching from the line connecting two endomolaria.

Palatine index and palatine height index were calculated using the following formulae.

- Palatine index = Breadth (d) / Length (c) x 100.

- Palatine height index $=$ Height $(h) /$ Breadth (d) $\times 100$.

The results obtained were tabulated and statistically analysed.

Fig.1: Morphometric measurements of hard palate. a) Length of pre-maxilla. $b$ ) Length of palatine process of maxilla. d) Breadth of palate.

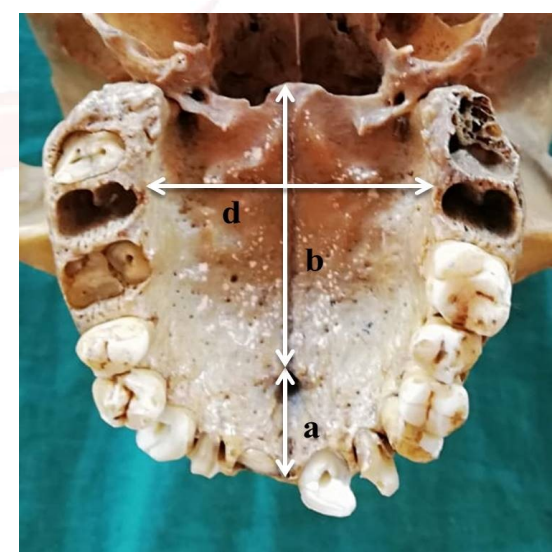

Fig. 2: Morphometric measurements of hard palate. c)Length of hard palate. e) Distance between greater palatine foramen and Middle maxillary suture.

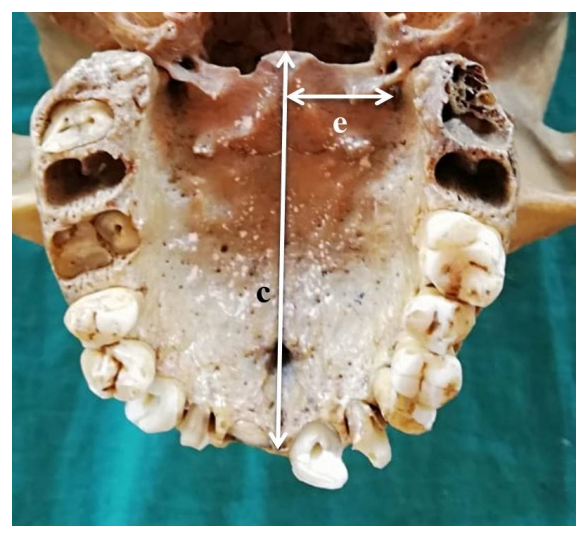




\section{RESULTS}

The length of the pre-maxilla (a) in the present study was $10.86 \mathrm{~mm} \pm 2.06 \mathrm{~mm}$ (Mean \pm SD) and the length of palatine process of maxilla (b) was found to be $39.59 \mathrm{~mm} \pm 2.14 \mathrm{~mm}$ (Mean \pm SD) (Table 1). The length (c), breadth (d) and height (h) of the hard palate in the present study was found to be $50.45 \mathrm{~mm} \pm 2.86 \mathrm{~mm}, 39.38 \mathrm{~mm} \pm 2.28$ $\mathrm{mm}$ and $10.31 \mathrm{~mm} \pm 2.21 \mathrm{~mm}$ (Mean $\pm \mathrm{SD}$ ) respectively (Table 2)

Table 1: Contribution of pre-maxilla and palatine process of maxilla to hard palate.

\begin{tabular}{|c|c|c|}
\hline & Mean & $\begin{array}{c}\text { Standard } \\
\text { Deviation }\end{array}$ \\
\hline Length of Pre-maxilla (a) & $10.86 \mathrm{~mm}$ & $2.06 \mathrm{~mm}$ \\
\hline Length of palatine process of maxilla (b) & $39.59 \mathrm{~mm}$ & $2.14 \mathrm{~mm}$ \\
\hline
\end{tabular}

Table 2: Measurements of Hard palate.

\begin{tabular}{|c|c|c|}
\hline & Mean & $\begin{array}{c}\text { Standard } \\
\text { Deviation }\end{array}$ \\
\hline Length of hard palate (c) & $50.45 \mathrm{~mm}$ & $2.86 \mathrm{~mm}$ \\
\hline Breadth of hard palate (d) & $39.38 \mathrm{~mm}$ & $2.28 \mathrm{~mm}$ \\
\hline Height of hard palate (h) & $10.31 \mathrm{~mm}$ & $2.21 \mathrm{~mm}$ \\
\hline
\end{tabular}

The distance between the GPF and MMS (e) in this study was found to be $14.80 \mathrm{~mm} \pm 1.14 \mathrm{~mm}$ (Mean \pm SD) on the right side and $14.83 \mathrm{~mm} \pm 1.08 \mathrm{~mm}$ (Mean \pm SD) (Table 3). In the present study, $82 \%$ of the skulls showed GPFs to be located opposite $3^{\text {rd }}$ molars and the remaining $18 \%$ of skulls showed GPFs to be located between $2^{\text {nd }}$ and $3^{\text {rd }}$ molars. We dint find any skull showing GPFs located opposite $2^{\text {nd }}$ molar in our study (Table 4 ).

Table 3: Distance between GPF and middle maxillary suture (e).

\begin{tabular}{|c|c|c|c|}
\hline \multicolumn{2}{|c|}{ Right side } & \multicolumn{2}{c|}{ Left side } \\
\hline Mean & $\begin{array}{c}\text { Standard } \\
\text { Deviation }\end{array}$ & Mean & $\begin{array}{c}\text { Standard } \\
\text { Deviation }\end{array}$ \\
\hline $14.80 \mathrm{~mm}$ & $1.14 \mathrm{~mm}$ & $14.83 \mathrm{~mm}$ & $1.08 \mathrm{~mm}$ \\
\hline
\end{tabular}

Table 4: Position of GPF.

\begin{tabular}{|c|c|c|}
\hline Position & Right side & Left side \\
\hline Opposite $3^{\text {rd }}$ molars & $40(80 \%)$ & $42(84 \%)$ \\
\hline Between $2^{\text {nd }}$ and 3 ${ }^{\text {rd }}$ molars & $10(20 \%)$ & $08(16 \%)$ \\
\hline Opposite $2^{\text {nd }}$ molars & ---- & --- \\
\hline Total & 50 & 50 \\
\hline
\end{tabular}

The palatine index of the present study showed that, $66 \%$ of the skulls were narrow (Leptostaphyline), $18 \%$ of the skulls were intermediate
(Mesostaphyline) and $16 \%$ of skulls were wide (Brachystaphyline) (Table 5). The palatine height index of the present study showed that, $56 \%$ of the skulls were low (Chamestaphyline), and the remaining $44 \%$ of the skulls were intermediate (Orthostaphyline). We dint find any sample with high palatine height index (Hypistaphyline) (Table 6)

Table 5: Palatine index.

\begin{tabular}{|c|c|c|}
\hline & Samples (\%) & Types \\
\hline$<80 \%$ & $33(66 \%)$ & Leptostaphyline \\
\hline $80-85 \%$ & $09(18 \%)$ & Mesostaphyline \\
\hline$>85 \%$ & $08(16 \%)$ & Brachystaphyline \\
\hline
\end{tabular}

Table 6: Palatine height index.

\begin{tabular}{|c|c|c|}
\hline & Samples (\%) & Types \\
\hline$<27.9 \%$ & $28(56 \%)$ & Chamestaphyline \\
\hline $28-39.9 \%$ & $22(44 \%)$ & Orthostaphyline \\
\hline$>40 \%$ & ---- & Hypistaphyline \\
\hline
\end{tabular}

\section{DISCUSSION}

Among the studies in the past, Ajmani observed $64 \%$ of adult skulls had GPF located opposite $3^{\text {rd }}$ molar tooth [5]. A study conducted by Saralaya and Nayak showed the same in $74 \%$ of skulls [6] while Bruno et al., observed it in $54 \%$ of skulls [7]. In our present study, GPF was found be opposite $3^{\text {rd }}$ molar tooth in $82 \%$ of skulls and between $2^{\text {nd }}$ and $3^{\text {rd }}$ molars in $18 \%$ of skulls.

The distance between GPF and MMS in a study conducted by Ajmani was found to be $14.7 \mathrm{~mm}$ on the right and $14.6 \mathrm{~mm}$ on the left [5]. Saralaya reported it to be $14.7 \mathrm{~mm}$ on both the sides [6]. Bruno $\mathrm{R}$ and colleagues reported the distance to be $14.68 \mathrm{~mm}$ on the right and $14.44 \mathrm{~mm}$ on the left side [7]. Westmoreland and Blanton had a mean of $14.8 \mathrm{~mm}$ on the right and $15.0 \mathrm{~mm}$ on the left [8] which was similar to the results obtained in our present study. The variation seen in the position of GPF may be attributed to the sutural growth between the maxilla and palatine bone. With the eruption of posterior teeth, the antero-posterior length of the palate increases [9].

A study by Hassanali on the African skulls of Kenya, the palatine index was found to be brachystaphyline in $43.2 \%$ of skulls. Palatine height index in the same study reported $40 \%$ of skulls to be chamestaphyline, $57 \%$ of skulls to be orthostaphyline and only $3 \%$ of skulls were hypistaphyline [10]. Study by Varalakshmi etal, 
showed $66 \%$ of skulls were leptostaphyline, $18.5 \%$ were mesostaphyline and $15.5 \%$ were brachystaphyline [11] similar to the results obtained in our study. Palatine height index in a study by Varalakshmi etal showed $72.3 \%$ of skulls were chamestaphyline, $26.1 \%$ were orthostaphyline and remaining 1.6\% were hypistaphyline [11]. In our study, 56\% were chamestaphyline and the remaining $44 \%$ were orthostaphyline.

\section{CONCLUSION}

The present study identifies the commonest location of greater palatine foramen to be opposite the $3^{\text {rd }}$ maxillary molars. This information will be useful to clinicians to block the greater palatine nerve at greater palatine foramen to perform various procedures on hard and soft palate. The knowledge on the morphometry of hard palate from the present study is useful in comparing the skulls of Indian origin with skulls of different races and ethnicity.

\section{ACKNOWLEDGEMENTS}

We acknowledge the support and co-operation from the Head \& the staffs of Department of Anatomy, K S Hegde Medical Academy, NITTE (Deemed To BE University), Mangaluru, India.

\section{Conflicts of Interests: None}

\section{REFERENCES}

[1]. Standring $S$, Borley NR, Collins P, Crossman AR, Gatzoulis MA, Healy JC. Oral Cavity. In: Standring S, editor. Gray's Anatomy - The Anatomical Basis Of Clinical Practice, $40^{\text {th }}$ ed. London: Elsevier Churchill Livingstone; 2008. p. 502.

[2]. Djuric-Srejic M. Letic V, Zivanovic S. New Facial Measurement Used In The Determination Of Palatine Index And Thickness Of The Mandibular Bodylindex. Hum. Evol. 2001;16(24):143-9.
[3]. Haward-Swirzinski K, Edwards PC, Saini TS, Norton NS. Length And Geometric Patterns Of The Greater Palatine Canal Observed In Cone Beam Computed Tomography. Int J Dent. 2010:2010. Article ID 292753, 6 pages. http://dx.doi.org/10.1155/2010/ 292753

[4]. Vinay KV, Beena DN and Vishal K. Morphometric Analysis Of The Greater Palatine Foramen In South Indian Adult Skulls. International Journal of Basic and Applied Medical Sciences. 2012; 2(3): 5-8.

[5]. Ajmani ML. Anatomical variation in position of the greater palatine foramen in the adult human skulls. J Anat 1994; 184: 635-637.

[6]. Saralaya V, Nayak SR . The relative position of the greater palatine foramen in dry Indian skulls. Singapore Med J 2007; 48: 1143-1146.

[7]. Bruno R. Chrcanovic, Antonio L. N. Custodio. Anatomical variation in the position of the greater palatine foramen. Journal of Oral Science 2010; 52 (1): 109-113.

[8]. Westmoreland EE, Blanton PL. An analysis of the variations in position of the greater palatine foramen in the adult human skull, Anat Rec 1982; 204: 383-388.

[9]. Slavkin HC, Canter MR, Canter SR. An anatomical study of the pterygomaxillary region in the craniums of infants and children. Oral Surg 1966; 21 : 225-235.

[10]. Hassanali J, Mwaniki D. Palatal analysis and osteology of the hard palate of the Kenyan Africanskulls, Ant Rec 1984; 209: 273-280.

[11]. Varalakshmi KL, Sangeeta MM, Naik SN, Acharya A. An osteological study of morphometry of hard palate and its importance. Int J Res Med Sci 2015;3:2210-3.

How to cite this article:

Sachin K S, Divya P, Chaitra D, Martin LA. MORPHOMETRIC STUDY

OF BONY PALATE AMONG DRY SKULLS OF SOUTH INDIA

POPULATION. Int J Anat Res 2019;7(3.2):6847-6850. DOI:

10.16965/ijar.2019.240 